Nat. Hazards Earth Syst. Sci., 17, 1795-1810, 2017

https://doi.org/10.5194/nhess-17-1795-2017

(C) Author(s) 2017. This work is distributed under

the Creative Commons Attribution 3.0 License.

\title{
Revisiting the synoptic-scale predictability of severe European winter storms using ECMWF ensemble reforecasts
}

\author{
Florian Pantillon, Peter Knippertz, and Ulrich Corsmeier \\ Institute of Meteorology and Climate Research, Karlsruhe Institute of Technology, Karlsruhe, Germany \\ Correspondence to: Florian Pantillon (florian.pantillon@kit.edu)
}

Received: 30 March 2017 - Discussion started: 31 March 2017

Revised: 15 September 2017 - Accepted: 18 September 2017 - Published: 19 October 2017

\begin{abstract}
New insights into the synoptic-scale predictability of 25 severe European winter storms of the 1995-2015 period are obtained using the homogeneous ensemble reforecast dataset from the European Centre for Medium-Range Weather Forecasts. The predictability of the storms is assessed with different metrics including (a) the track and intensity to investigate the storms' dynamics and (b) the Storm Severity Index to estimate the impact of the associated wind gusts. The storms are well predicted by the whole ensemble up to 2-4 days ahead. At longer lead times, the number of members predicting the observed storms decreases and the ensemble average is not clearly defined for the track and intensity. The Extreme Forecast Index and Shift of Tails are therefore computed from the deviation of the ensemble from the model climate. Based on these indices, the model has some skill in forecasting the area covered by extreme wind gusts up to 10 days, which indicates a clear potential for early warnings. However, large variability is found between the individual storms. The poor predictability of outliers appears related to their physical characteristics such as explosive intensification or small size. Longer datasets with more cases would be needed to further substantiate these points.
\end{abstract}

\section{Introduction}

One of the most important natural hazards over Europe arises from winter storms associated with low-pressure systems from the North Atlantic, also referred to as cyclonic windstorms (Lamb and Frydendahl, 1991). These storms are therefore the focus of various fields of research involving the weather and climate communities as well the wind power and reinsurance industries. At longer timescales, a crucial ques- tion lies in the trends in frequency and intensity of winter storms in the current and future climate. To date, there is little agreement between climate models and between identification methods (see Feser et al., 2015, for a review). The intensity of storms is not necessarily related to their impact and storm losses are better estimated from the strength of winds or wind gusts exceeding a certain threshold (Klawa and Ulbrich, 2003). Numerous studies are therefore dedicated to the estimation of the footprint of strong winds and gusts associated with winter storms as well as their return periods (DellaMarta et al., 2009; Hofherr and Kunz, 2010; Donat et al., 2011; Haas and Pinto, 2012; Seregina et al., 2014). These studies often require a combination of dynamical and statistical models to adequately represent the footprints.

At shorter timescales, most studies concentrate on the detailed investigation of case studies of severe storms and on the ability of numerical weather prediction systems to forecast them. Although the general life cycle of extratropical cyclones has been known for almost one century, the intensification of storms and the generation of strong winds involve physical processes of different scales that are still not fully understood (Hewson and Neu, 2015). Recent advances have resulted from the attention drawn by devastating storms. The damaging winds over southeast England during the "Great Storm" of October 1987, which were observed at the tip of the cloud head bounding the bent-back front, now form the archetypal example of a phenomenon known as the sting jet (Browning, 2004). The destructions caused by storm Lothar over central Europe in December 1999 revealed the importance of diabatic processes in a way similar to a diabatic Rossby wave for the rapid intensification of the storm over the North Atlantic (Wernli et al., 2002). The severe wind gusts observed during the passage of storm Kyrill in Jan- 
uary 2007 over central Europe finally emphasized the role of convection embedded in the cold front including the formation of cold-season derechos (Fink et al., 2009; Gatzen et al., 2011).

These historical storms were poorly forecast when they occurred and thus captured even greater attention in the weather research community, which resulted in prolific scientific literature on specific storms. In particular, Buizza and Hollingsworth (2002) recognised early the potential of the ensemble prediction system of the European Centre for Medium-Range Weather Forecasts (ECMWF) to predict the storms Anatol, Lothar and Martin in December 1999. They showed that ensemble forecasts offer a more consistent picture between different initialisation times than deterministic forecasts and additionally provide early indications of the chance of an intense storm. Lalaurette (2003) further showed that the extremeness of the ensemble as a whole, measured by its deviation from the model climate, allows identifying areas of unusually strong winds up to $120 \mathrm{~h}$ lead time in the case of Lothar, although failing in the case of Martin. Petroliagis and Pinson (2014) and Boisserie et al. (2016) recently extended this method to longer periods with, respectively, operational and retrospective forecasts. While they found contrasting results from case to case, the authors confirmed the potential of ensemble forecasts for the early warning of severe European storms.

A more statistical approach was proposed by Froude et al. (2007a, b), who identified storms as objects with a tracking algorithm and systematically compared their position and intensity between forecasts and analyses. They investigated the predictability of a large number of extratropical cyclones in both deterministic and ensemble forecasts and found a slow bias in the track forecasts. For this large sample ranging from shallow to deep cyclones, they further found large errors in the intensity forecasts but contrasting biases that depend on the region and on the model. Pirret et al. (2017) recently applied this tracking approach to severe European storms in operational ECMWF ensemble forecasts and found a negative bias in intensity in addition to the slow bias in track. They further investigated the relative contribution of diabatic and baroclinic processes to the intensification of the storms. Although they succeeded in showing a significant correlation between the track and the dynamics of the storms, they struggled to find an impact on predictability. Their results were, however, limited by the use of operational forecasts, whose skill improves with updates in the model version and with increases in the horizontal resolution in particular.

Building on these previous studies, the predictability of severe European winter storms is systematically investigated here for a 20-year period in an ensemble prediction system by taking advantage of the recently available ECMWF retrospective forecasts (reforecasts; Hagedorn et al., 2008, 2012). While reforecasts are originally designed for calibrating the operational forecasts, which result in a significant improvement in forecast skill, they also represent a homogeneous dataset that is ideal for comparing historical events (Hamill et al., 2006, 2013). The predictability of severe storms is thus not restricted to single case studies here but encompasses a number of events that allow a statistical analysis. Situations with less severe or no storms are also included to check whether the results are biased by the focus on extreme events. Furthermore, three methods are combined here to assess the predictability of the storms. In addition to the track and intensity and to the unusually strong winds, a third, novel approach is added for the impact of the storms measured by their gust footprint. To the best of the authors' knowledge, the impact of severe winter storms has been extensively studied in the climatological community but its predictability has not been documented in the peer-reviewed literature.

The paper is organised as follows. Section 2 describes the reforecast and reanalysis model data and the selection of severe storms, as well as the three different methods used to assess the predictability of the storms in these data. Section 3 presents the results obtained for general storm characteristics and using either the ensemble average and spread or individual ensemble members. Section 4 discusses the skill for early warning on the 5-10 day timescale using either selected storms or the whole dataset. Section 5 finally gives the conclusions of the study.

\section{Data and methods}

\subsection{Model data}

This study makes extensive use of the ensemble reforecast from the ECMWF (Hagedorn et al., 2008, 2012). The ensemble reforecast is based on the current version of the operational model but with a lighter configuration to reduce computing time. It is initialised from the ECMWF Retrospective Analysis (ERA) Interim (Dee et al., 2011) and ensemble members are obtained from initial perturbations computed with singular vectors. In contrast to the operational model, stochastic perturbations of physical processes are not applied to the ensemble members. Since mid-May 2015, the ensemble reforecast contains 10 perturbed members in addition to a control member and it is run twice a week - every Monday and Thursday at 00:00 UTC - for the current date in the past 20 years. Until mid-March 2016, when the model resolution was upgraded, the horizontal grid spacing was approximately $30 \mathrm{~km}$ for the first 10 days and was then coarser at longer lead times until 46 days. All 10-day ensemble reforecasts computed between mid-October 2015 and mid-March 2016 are used here, which represents a homogeneous dataset of nearly 10000 individual reforecasts for the winter seasons 1995/1996 to 2014/2015.

The reforecasts are verified against ERA-Interim reanalyses, which are available since 1979 and are computed with a horizontal grid spacing of approximately $80 \mathrm{~km}$, corresponding to a 2006 version of the operational model (Dee 
et al., 2011). The verification is based on the 6-hourly meansea-level pressure (MSLP) for the track and intensity of the storms and on the daily maximum wind gusts for the other metrics. The wind gusts are available in the ERA-Interim dataset from short-range reforecasts initialised from the reanalyses at 00:00 and 12:00 UTC. They are computed from the wind speed on the lowest model level and a turbulent component based on a similarity relation between the variability of the surface wind and the friction velocity (Panofsky et al., 1977). In the ensemble reforecast, which uses a more recent model version, the computation of wind gusts includes an additional component based on the low-level wind shear in convective situations (Bechtold and Bidlot, 2009). This additional component is expected to contribute to the strongest wind gusts when convection is embedded in the cold front.

Although the ERA-Interim dataset has been widely used for climatological studies of winter storms, it has recently been criticised for underestimating the deepening rate of storms and the strength of wind gusts (Hewson and Neu, 2015). In particular, the relatively low horizontal resolution of ERA-Interim is not sufficient to represent the mesoscale structure of the storms. Capturing sting jets for instance, which are responsible for some of the most damaging wind gusts within storms, would require a horizontal grid spacing of 10-20 km (Hewson and Neu, 2015). Furthermore, gust parameterisations underestimate the observed strength of wind gusts over complex terrain, even at much higher resolution (Stucki et al., 2016). As the focus here is on the synopticscale aspects of winter storms, these limitations of ERAInterim are likely rather unimportant. The comparison with ensemble forecasts remains fair, because their horizontal resolution is not sufficient to capture the strongest gusts either and because the verification of wind gusts is based on values relative to the model climate rather than on absolute values. Finally, modelled wind gusts well sample storms with a large displacement velocity because they are computed as the maximum values over all model time steps between 6-hourly outputs. They are therefore preferred to modelled wind speeds, which are output as 6-hourly instantaneous values only.

\subsection{Selection of storms}

Significant historical storms are selected to investigate their predictability in the ensemble reforecast. The selection is made using the "XWS open-access catalogue of extreme European windstorms" provided by Roberts et al. (2014), which contains the 50 most severe storms for the 1979-2012 period. The catalogue is based on ERA-Interim dynamically downscaled with the Met Office Unified Model and recalibrated with observations. The majority of the 50 storms affected the UK more than any other European country. This is not surprising, considering the location of the UK at the end of the Atlantic storm track. However, it may be exaggerated by the selection of storms based on wind gusts above a fixed threshold of $25 \mathrm{~m} \mathrm{~s}^{-1}$, which is less often exceeded over continen-
Table 1. Chronological list of the 25 investigated storms with their characteristics in ERA-Interim on the day of maximum intensity: minimum mean-sea-level pressure (MSLP), Storm Severity Index (SSI) and area of central Europe covered by gusts exceeding the local 98th percentile. The values corresponding to the deepest, most severe and smallest storms cited in the text are emphasized in bold.

\begin{tabular}{|c|c|c|c|c|c|}
\hline Symbol & Name & Date & $\operatorname{MSLP}(\mathrm{hPa})$ & $\mathrm{SSI}\left(\times 10^{-3}\right)$ & Area $(\%)$ \\
\hline$\square$ & Jennifer (1996) & 07 Feb 1996 & 976 & 3.0 & 11.1 \\
\hline$\square$ & Lili & 28 Oct 1996 & 970 & 0.40 & 7.3 \\
\hline$\square$ & Romy & 06 Nov 1996 & 960 & 0.48 & 20.8 \\
\hline$\square$ & Yuma & 24 Dec 1997 & 974 & 0.35 & 5.8 \\
\hline$\square$ & Fanny & 04 Jan 1998 & 966 & 2.0 & 16.6 \\
\hline 0 & Xylia & 28 Oct 1998 & 966 & 0.64 & 28.3 \\
\hline$\bigcirc$ & Silke (Stephen) & 26 Dec 1998 & 950 & 2.4 & 21.0 \\
\hline$\bigcirc$ & Anatol & 03 Dec 1999 & 956 & 5.1 & 28.7 \\
\hline 0 & Lothar & 26 Dec 1999 & 976 & 15 & 23.7 \\
\hline 0 & Martin & 27 Dec 1999 & 969 & 9.7 & 20.5 \\
\hline$\triangle$ & Oratia (Tora) & 30 Oct 2000 & 949 & 2.8 & 24.8 \\
\hline$\triangle$ & Jennifer (2002) & 28 Jan 2002 & 956 & 1.7 & 28.1 \\
\hline$\triangle$ & Jeanett & 27 Oct 2002 & 975 & 3.8 & 26.1 \\
\hline$\triangle$ & Erwin (Gudrun) & 08 Jan 2005 & 961 & 6.4 & 33.0 \\
\hline$\triangle$ & Gero & 11 Jan 2005 & 948 & 1.9 & 7.9 \\
\hline+ & Kyrill & 18 Jan 2007 & 963 & 6.7 & 35.5 \\
\hline+ & Emma & 01 Mar 2008 & 960 & 2.4 & 34.7 \\
\hline+ & Klaus & 24 Jan 2009 & 966 & 13 & 12.8 \\
\hline+ & Quinten & 09 Feb 2009 & 976 & 0.59 & 9.2 \\
\hline+ & Xynthia & $27 \mathrm{Feb} 2010$ & 968 & 2.7 & 8.7 \\
\hline$\times$ & Joachim & 16 Dec 2011 & 966 & 3.5 & 31.0 \\
\hline$x$ & Patrick (Dagmar) & 26 Dec 2011 & 965 & 0.35 & 10.1 \\
\hline$\times$ & Ulli & 03 Jan 2012 & 955 & 1.6 & 27.7 \\
\hline$\times$ & Christian (St Jude) & 28 Oct 2013 & 969 & 0.91 & 18.7 \\
\hline$\times$ & Xaver & 05 Dec 2013 & 962 & 2.3 & 34.9 \\
\hline
\end{tabular}

tal Europe (Roberts et al., 2014). The selection thus differs from other catalogues based on alternative criteria that may be more relevant for specific regions (e.g. Stucki et al., 2014, for Switzerland).

The catalogue is available online at http://www. europeanwindstorms.org/ and has been updated with two additional storms for the winter season 2013/2014. Following the time period of the ensemble reforecast, the storms that occurred between mid-October and mid-March from 1995/1996 to 2014/2015 are selected here. One storm occurring in late March is excluded through the restriction to the winter period, expecting that the mid-October to mid-March time span of the reforecast is relevant for severe storms. The selection results in the 25 storms listed in Table 1. The storm names are those given by the Free University of Berlin when available, with alternative names in brackets when relevant. They were completed for a few storms with respect to the original catalogue of Roberts et al. (2014). 
(a) Track and intensity

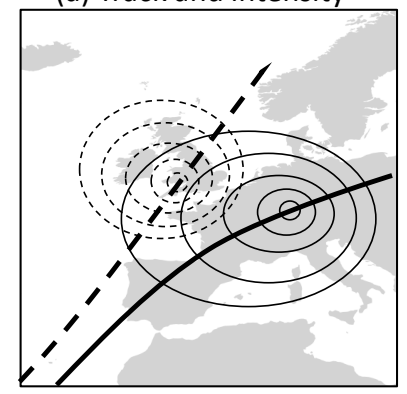

(b) Strength of gusts

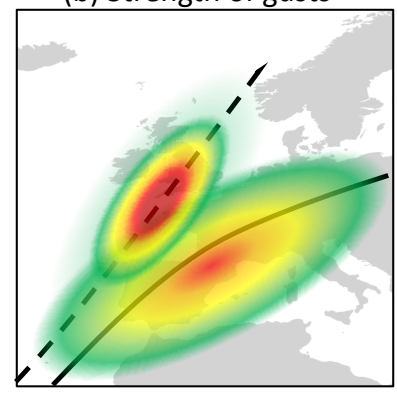

(c) Area covered by gusts

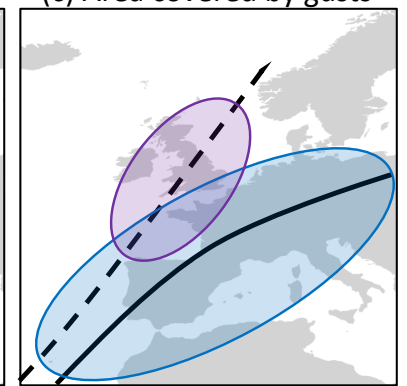

Figure 1. Schematic depiction of the three metrics used to evaluate the predictability of storms: based on the track and intensity of the storms (a), based on the strength of wind gusts (b) and based on the area covered by unusually strong gusts (c). See text for details.

\subsection{Evaluation of predictability}

Three metrics are combined to assess the predictability of the storms with regard to different properties: the dynamics are evaluated with the track and intensity of the storms (Fig. 1a; Sect. 2.3.1), the impact is estimated with the footprint of wind gusts (Fig. 1b; Sect. 2.3.2) and the potential for early warnings is computed from the area of predicted gusts that are well above the model climate (Fig. 1c; Sect. 2.3.3).

Either the ensemble average or the individual members are used for the verification of the reforecasts of the selected storms based on these metrics. When the whole reforecast dataset is considered, the skill is estimated with appropriate scores. In particular, the Brier score (Brier, 1950) measures the ability to predict if an event will occur or not. It can be split into reliability, resolution and uncertainty components (Murphy, 1973). The reliability component measures the ability of the forecast to predict the observed frequency of events. A perfect reliability can be achieved with a climatological forecast and is thus not sufficient to be useful. In contrast, the resolution component measures the ability of the forecast to distinguish between events and non-events, which cannot be achieved with a climatological forecast. The uncertainty component finally measures the sampling uncertainty inherent to the events. The Brier score can further be compared to a climatological forecast to obtain the Brier skill score (BSS), which is in turn split into

$\mathrm{BSS}=1-B_{\mathrm{rel}}-B_{\mathrm{res}}$,

with reliability and resolution components $B_{\text {rel }}$ and $B_{\text {res }}$ (e.g. Jolliffe and Stephenson, 2012).

\subsubsection{Storm tracking}

The 25 selected storms are tracked both in ERA-Interim and in the members of the ensemble reforecast, using the algorithm described by Pinto et al. (2005) and originally developed by Murray and Simmonds (1991). In a first step, maxima are identified in the Laplacian of MSLP interpolated on a polar stereographic grid then minima in MSLP are looked for in their vicinity. The Laplacian of MSLP is closely related to the quasi-geostrophic vorticity; thus the algorithm is similar to tracking maxima in low-level vorticity. In a second step, the minima of MSLP are connected between subsequent model outputs every $6 \mathrm{~h}$, using a predicted velocity based on both the previous displacement and the steering by the environment. As the focus is on severe storms here, the obtained tracks are filtered to exclude storms with a weak Laplacian of MSLP below $0.8 \mathrm{hPa}\left({ }^{\circ} \text { great circle }\right)^{-2}$ or with a duration of less than $24 \mathrm{~h}$. However, the algorithm results in a large number of tracks, among which the storms of interest need to be identified.

Identifying the storms in ERA-Interim is straightforward because the selection of severe storms is based on the same dataset. For each of the 25 storms, the reference time and position of minimum MSLP given by Roberts et al. (2014) are searched for in the tracks obtained from the algorithm. The closest track is unambiguously identified this way and matches the reference track, although differences may arise, particularly at the beginning and end. As first suggested by Raible et al. (2008) and later emphasized by Neu et al. (2013), such differences are a common issue when comparing storm tracking algorithms, which usually agree well for the mature phase of deep cyclones but differ during the phases of cyclogenesis and cyclolysis. In particular, the algorithm of Pinto et al. (2005) tends to identify the cyclones earlier than others. Neu et al. (2013) emphasise that there is no best way of tracking storms, because there is no single definition of extratropical cyclones. As the same algorithm is applied here to both ERA-Interim and the reforecasts, potential biases due to the tracking method would likely cancel out.

In the reforecast, identifying the storms is less straightforward even at short lead times and quickly becomes ambiguous because the tracks diverge from ERA-Interim when the lead time increases. In earlier studies, Froude et al. (2007a, b) applied strict criteria in the location, timing and duration of tracks to identify storms in forecasts. While such criteria may be required for statistical studies, they would reject too many ensemble members for the sample of storms consid- 
(a) Identification during first common occurence

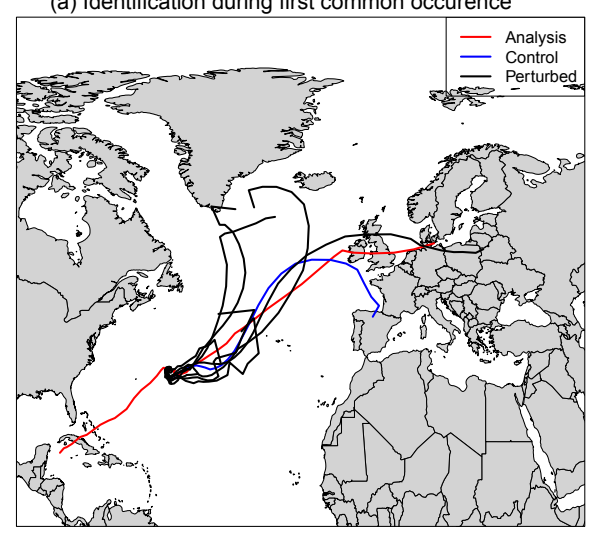

(b) Identification during maximum intensity

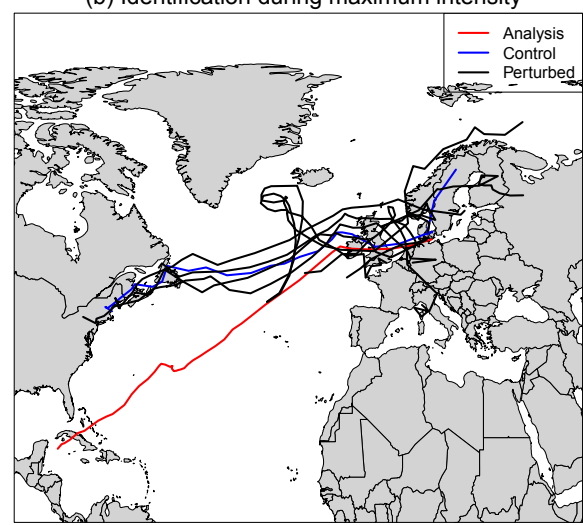

Figure 2. Example of the identified tracks of ex-hurricane Lili in the 6-day ensemble reforecast initialised on 22 October 1996 closest to ERAInterim during the $24 \mathrm{~h}$ period of first common occurrence on 22 October (a) and of maximum intensity in ERA-Interim on 28 October (b).

ered here, in particular at long lead time, and thus would bias the results towards "good" members. Instead, the track closest to ERA-Interim is identified in each ensemble member without arbitrary criteria, based on the great-circle distance averaged over a $24 \mathrm{~h}$ period. Two methods are compared for the definition of the $24 \mathrm{~h}$ period. In the first method, the period is defined as the first $24 \mathrm{~h}$ overlap between the track in the ensemble member and in ERA-Interim. If the track is not present at the time of initialization, it is further constrained to start in the ensemble member within $48 \mathrm{~h}$ of its first occurrence in ERA-Interim. In the second method, the period is simply defined as the day of maximum intensity.

The two methods are illustrated for the 7-day reforecast of the storm that hit the British Isles on 28 October 1996 (Table 1). The storm took its origin in Hurricane Lili, which reached Europe after crossing the North Atlantic and undergoing extratropical transition (Browning et al., 1998). With the first method, the identified tracks start from the same location, because the storm is present in the reforecast at the time of initialization (Fig. 2a). They later diverge and only two of them reach Europe, whereas the others remain over the central North Atlantic. With the second method in contrast, the identified tracks all reach Europe, as expected from the identification on the day of maximum intensity (Fig. 2b). However, they start from different regions spreading from the western to the eastern North Atlantic. In particular, no single track takes its origin in Hurricane Lili, i.e. the two methods do not show any common track. Although this case of extratropical transition is unique among the selected storms, it illustrates the difficulty of identifying storms in the reforecast. The most relevant method depends on the aims of the analysis; the first method focusing on the dynamics of the storm and the second one on its impact. Both methods are therefore used here.

\subsubsection{Storm Severity Index (SSI)}

While the intensity of a storm is commonly measured with its minimum MSLP, its severity mostly depends on the strength of the wind gusts, which is also controlled by the pressure gradient at the synoptic scale and by additional factors at the mesoscale and turbulent scale. In particular, insured losses have been shown to scale with the third power of the strongest wind gusts. Following Klawa and Ulbrich (2003) for observations and Leckebusch et al. (2007) for model data, an SSI is therefore defined as

$\mathrm{SSI}=\left(\frac{v_{\max }}{v_{98}}-1\right)^{3}$

if $v_{\max }>v_{98}$ and $\mathrm{SSI}=0$ otherwise, with $v_{\max }$ the daily maximum wind gust and $v_{98}$ its local 98th climatological percentile. The scaling with $v_{98}$ accounts for the local adaptation to wind gusts, whose impact on infrastructure is weaker in exposed areas such as coasts and mountains than in the continental flatlands for the same absolute wind speed (Klawa and Ulbrich, 2003). The climatology of wind gusts is computed separately for ERA-Interim and the reforecast but for the same period of interest, i.e. mid-October-midMarch 1995/1996-2014/2015. The resulting values of $v_{98}$ are higher in the reforecast, likely due to the higher model resolution but possibly also due to other changes to the ECMWF model. In addition, wind gusts are abnormally high over topography in the first $6 \mathrm{~h}$ output of the reforecast. As this does not appear in subsequent outputs, it is likely related to the spin-up of the model when the higher-resolution reforecast is initialised from the lower-resolution reanalysis. The first $6 \mathrm{~h}$ output of the reforecast is thus omitted for computing both $v_{\max }$ and $v_{98}$.

As an example, the daily maximum gusts and the resulting SSI in ERA-Interim are shown in Fig. 3a and b, respectively, for storm Lothar on 26 December 1999. The strongest gusts are found over the Bay of Biscay but the highest SSI is found 

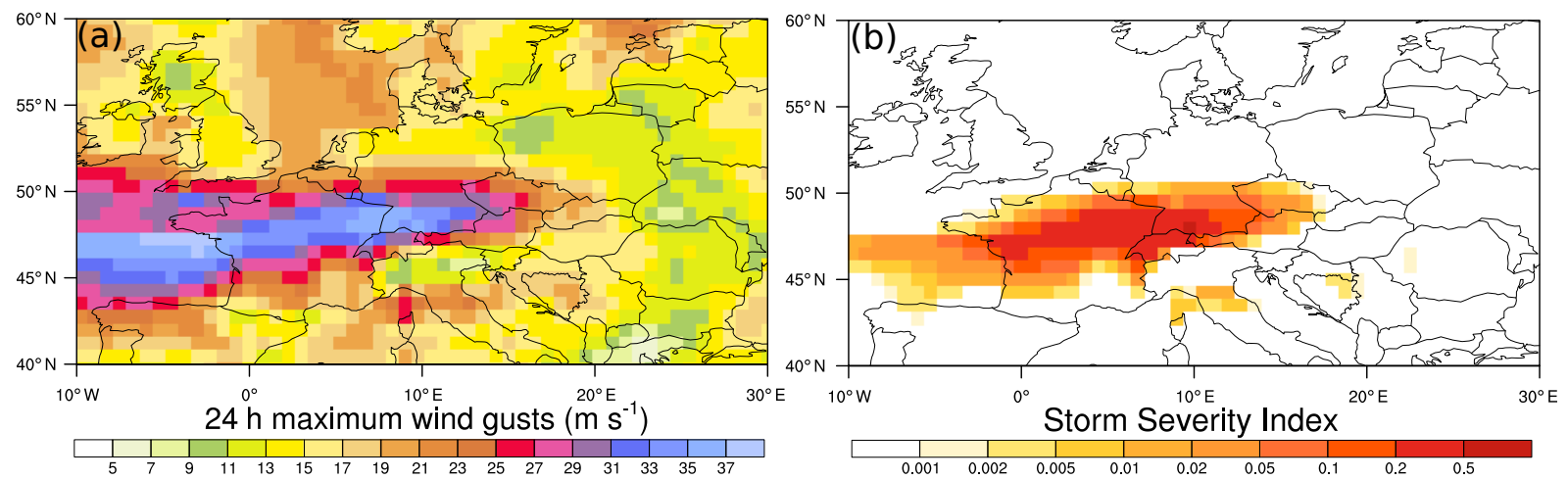

Figure 3. Example of the daily maximum wind gusts (a) and daily Storm Severity Index (b) for storm Lothar in ERA-Interim on 26 December 1999.

over southern Germany due to the lower values of the local model climatology. The SSI is then averaged over central Europe (defined as $40-60^{\circ} \mathrm{N}$ and $10^{\circ} \mathrm{W}-30^{\circ} \mathrm{E}$; corresponds to the map shown in Fig. 3) to give a single value for the total severity of the storm, which can then be compared with the reforecast. This method is equivalent to the SSI defined by Leckebusch et al. (2007). It is preferred to including the SSI along the track of the storm only, as e.g. in Roberts et al. (2014), because of the ambiguous identification of the tracks in the reforecast. Among the 25 investigated storms, Lothar exhibits the highest averaged SSI in ERA-Interim, followed by Klaus, Martin and Kyrill (Table 1). These four storms are responsible for the four highest insurance losses during the period of interest (Roberts et al., 2014), which suggests that the averaged SSI in ERA-Interim is a relevant measure of the severity of storms. Inaccuracies are still expected and attributed to mesoscale features that are not resolved by ERAInterim and by non-meteorological factors such as the density of population and the insured capital. Finally, although the impact of storms is expected from wind gusts over land mostly, the adjacent ocean areas are also included in the calculation of the SSI here to avoid large sensitivities to the predicted position of storms that track close to the coasts. Including the ocean also accounts at least partially for storm surges, the main impact of some severe storms (e.g. Xynthia; Ludwig et al., 2014).

\subsubsection{Extreme Forecast Index (EFI) and Shift of Tails (SOT)}

Forecasting extreme events is a challenge in numerical weather prediction, because predicted extremes tend to underestimate the magnitude of actual events. Lalaurette (2003) therefore introduced the EFI, which measures the extremeness of an ensemble forecast as compared to the model climate rather than to the observed climate. The original formulation of the EFI was revised by Zsóter (2006), who included a weighting function to emphasise the tails of the distribution and obtained
$\mathrm{EFI}=\frac{2}{\pi} \int_{0}^{1} \frac{p-F_{\mathrm{f}}(p)}{\sqrt{p(1-p)}} \mathrm{d} p$,

with $F_{\mathrm{f}}(p)$ the proportion of ensemble members lying below the $p$ quantile of the model climate. The EFI quantifies the deviation of an ensemble forecast from its climatological distribution with a unitless number between -1 (all members reach record-breaking low values) and +1 (record-breaking high values).

Zsóter (2006) also introduced the SOT as an additional index that focuses even more on the tail of the distribution

$\operatorname{SOT}(p)=-\frac{Q_{\mathrm{f}}(p)-Q_{\mathrm{c}}\left(p_{0}\right)}{Q_{\mathrm{c}}(p)-Q_{\mathrm{c}}\left(p_{0}\right)}$

with $Q_{\mathrm{f}}(p)$ and $Q_{\mathrm{c}}(p)$ the $p$ quantiles of the ensemble forecast and of the model climate, respectively. The SOT indicates whether a fraction of the ensemble members predicts an extreme event, even whether the rest of the members do not. Following Zsóter (2006), $p$ is taken as the 90th percentile, i.e. the top two members of the 11-member ensemble reforecast. As in the operational ECMWF configuration, $p_{0}$ is taken as the 99th percentile of the model climate, which is smoother than the 100th percentile (maximum) used by Zsótér (2006). A positive value of SOT thus means that at least two members predict an extreme event that belongs to the top percent of the model climate.

Both EFI and SOT are computed here for daily maximum wind gusts. For consistency with the SSI, the model climate is defined from the period mid-October to midMarch 1995/1996-2014/2015. This contrasts with the operational ECMWF configuration, where the model climate is defined for each forecast within a 1-month window centred around the initialization time. As the focus is on winter storms here, a seasonal model climate is preferred to avoid storms to be considered as more or less extreme depending on when they occur during the season. A longer period is also preferred to improve the representation of the 99th percentile 

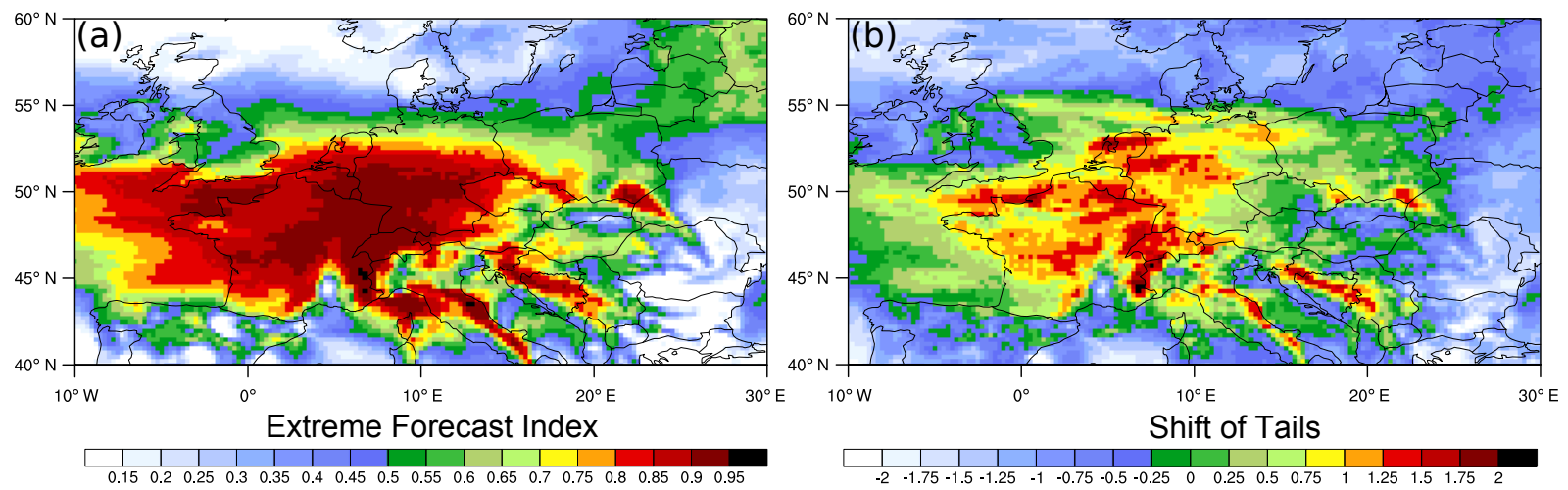

Figure 4. Example of the Extreme Forecast Index (a) and Shift of Tails (b) of daily maximum wind gusts for storm Lothar in the 6-day ensemble reforecast initialised on 21 December 1999 and valid on 26 December.

of the model climate, as the length of the operational configuration has been validated for precipitation and temperature but not for wind gusts (Zsoter et al., 2015). Finally, as in the operational configuration, the model climate is computed separately at each lead time to compensate for any drift of the reforecast.

Figure 4 illustrates the EFI and SOT for the 6-day reforecast of storm Lothar. High values of EFI spread over a broad region from the Atlantic Ocean to eastern Europe and exhibit stripes further eastward (Fig. 4a). Positive values of SOT also spread over a similar, broad region but the highest values are more concentrated (Fig. 4b). This is due to the stronger emphasis on the tail of the distribution based on two members in SOT rather than on the whole ensemble in EFI. A comparison with ERA-Interim in Fig. 3a indicates a skill of both EFI and SOT in predicting the strong gusts over parts of France, Switzerland and Germany. However, it also shows a discrepancy between high EFI or SOT and weaker gusts over other regions. This suggests a potential for warnings but with possible false alarms, as already noted by Lalaurette (2003). The use of EFI and SOT thus requires an appropriate balance between hit and false alarm rates (Petroliagis and Pinson, 2014; Boisserie et al., 2016).

\section{Predictability of storm characteristics}

\subsection{Position and intensity}

The predictability of the selected storms is first evaluated for the position and intensity obtained from the storm tracking algorithm. The storms are identified in the reforecast at the time of first occurrence and compared with ERA-Interim at the time of maximum intensity. As the 10-day reforecasts are computed every Monday and Thursday, three lead times are available for most storms but only two for those which occurred on a Sunday. The average bias and spread are computed for each storm and lead time with the median and median absolute deviation, respectively, which are preferred to the mean and standard deviation to ensure robust statistics despite the small number of ensemble members.

On average over all storms, the predicted MSLP remains close to ERA-Interim until day 4 but exhibits a clear positive bias from day 5 onwards; i.e. it underestimates the intensity of storms (black curve in Fig. 5a). The predicted MSLP also exhibits a large variability between the storms, which increases with increasing lead time (symbols in Fig. 5a). The most striking outlier is storm Gero (red triangle), which shows the largest positive biases with more than 60 and $40 \mathrm{hPa}$ on days 5 and 8 , respectively. Gero experienced an explosive cyclogenesis of $40 \mathrm{hPa}$ in $24 \mathrm{~h}$ to reach $948 \mathrm{hPa}$ on 11 January 2005, the deepest MSLP of the sample of storms (Table 1). The second and third deepest storms Oratia and Silke, which also experienced an explosive cyclogenesis, show contrasting positive and negative biases in MSLP depending on the lead time (green triangle and blue circle in Fig. 5a). Surprisingly, the predicted MSLP of Gero exhibits a negative bias on day 1, although this may be due to ERAInterim underestimating the actual intensity due to its coarse horizontal resolution.

Concerning the position, the predicted longitude exhibits a negative bias on average, i.e. the storms are too slow in the reforecast from day 4 onwards (black curve in Fig. 5b). A weak positive bias is present in the reforecast of the latitude but it does not appear to be significant (not shown). Similar to the predicted MSLP, the predicted longitude also exhibits a large variability between the storms, which increases with increasing lead time (symbols in Fig. 5b). Storm Gero is again an outlier with strong negative biases at days 5 and 8 (red triangles) but an even larger bias is found at day 7 for Lili (blue square). This storm formed in the tropics (Browning et al., 1998, see also Fig. 2), which is consistent with the poor predictability of the position during extratropical transition due to the difficulty to represent convective dynamics (e.g. Pantillon et al., 2013). However, this case is unique among the selected storms. Other cases that exhibit strong biases formed over very different regions, as e.g. Patrick over the southeast- 

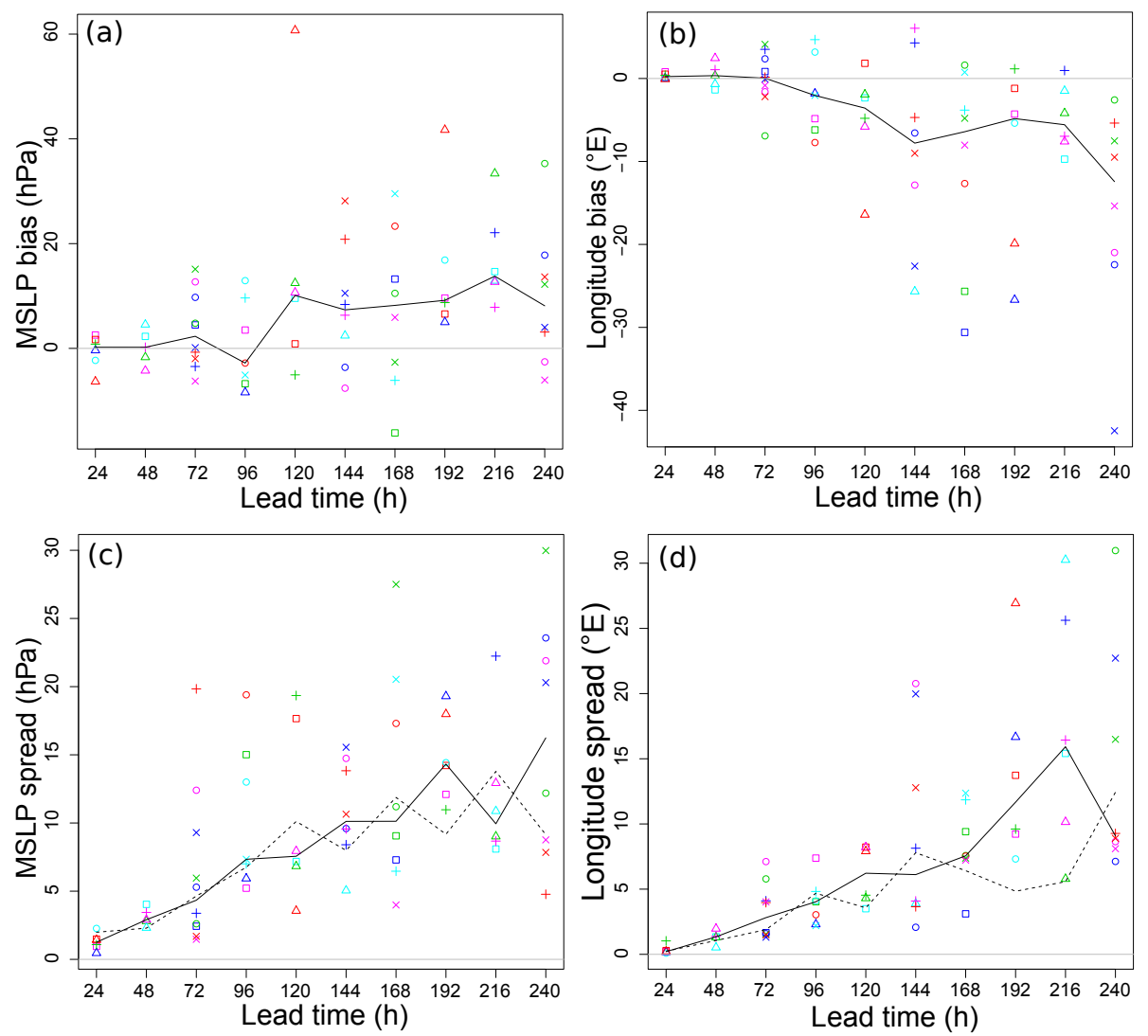

Figure 5. Position and intensity of the storms in the ensemble reforecast as identified at the time of first occurrence and compared on the day of maximum intensity: difference between the ensemble median and ERA-Interim (a, b) and median absolute deviation of the ensemble (c, d) in MSLP (a, c) and longitude (b, d). The symbols represent the storms as given in Table 1 and the solid black curve shows the median of the storms per lead time, while the dashed black curve in $(\mathbf{c}, \mathbf{d})$ further shows the median absolute error of the storms per lead time.

ern US (blue cross at day 10) and Jennifer (1996) over the eastern North Atlantic (green square at day 7). This emphasises how single factors can influence the predictability of specific storms.

As expected, the spread between the ensemble members increases with increasing lead time on average, both for the intensity (solid black curve in Fig. 5c) and the position (solid black curve in Fig. 5d). The spread is consistent with the median absolute error (dashed curve), which suggests that the ensemble reforecast is calibrated. However, the spread also shows a large variability between the storms and it does not necessarily match the error for individual storms. For instance, the storms with a strong bias mentioned above tend to exhibit a small spread. Inversely, the predicted MSLP of Joachim was very uncertain (green crosses at days 7 and 10 on Fig. 5c) due to the sensitivity to the phasing of the storm with a Rossby wave train over the western North Atlantic (Lamberson et al., 2016). Finally, the large uncertainty in the MSLP of Xynthia at day 3 (red plus) may be due to the strong influence of latent heat release during the unusual track over the subtropical North Atlantic (Ludwig et al., 2014).

\subsection{Ensemble average and individual members}

These results agree with findings of previous studies using earlier versions of the operational ECMWF ensemble forecast system. Froude et al. (2007b) also found a slow bias in a systematic evaluation of the track of extratropical cyclones, while Pirret et al. (2017) further found a low bias in intensity for severe European storms. This suggests that the speed is systematically underestimated for extratropical cyclones in general, while the intensity is underestimated for deep cyclones only. Despite these biases, Froude et al. (2007b) found a higher skill of the ensemble mean compared to the control forecast to predict the track and intensity of cyclones from day 3 onwards. This result raises the question of the limit of validity of the ensemble mean for the track of the storms, as the identification of storms becomes more ambiguous and the number of members containing the observed storms decreases when the lead time increases. Both factors may bias the ensemble average towards the tracks that are closer to the analysis and thus overestimate its skill. In the extreme case of Lili, this metric even becomes meaningless, because all members of the 10-day reforecast valid on the day of max- 
(a) Generous thresholds
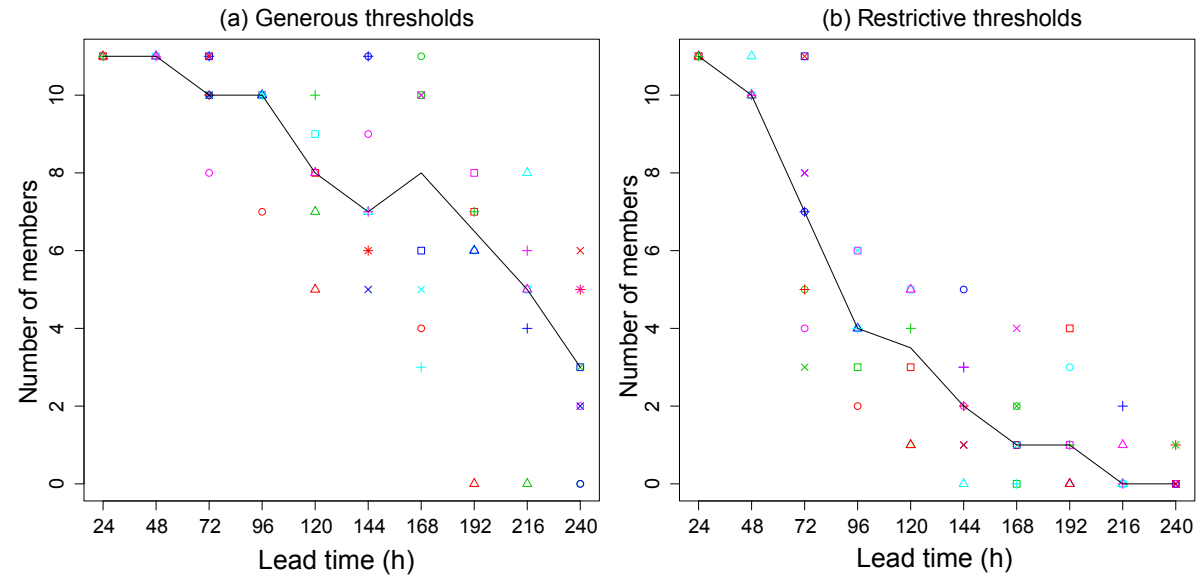

Figure 6. Position and intensity of the storms in the ensemble reforecast as identified and compared on the day of maximum intensity: number of ensemble members predicting the storm within $20 \mathrm{hPa}$ and $10^{\circ}$ great circle (a) or $10 \mathrm{hPa}$ and $5^{\circ}$ great circle (b) as compared to ERA-Interim in minimum MSLP and position, respectively. The symbols represent the storms as given in Table 1 and the black curve shows the median of the storms per lead time.

imum intensity have lost track of the storm on the day it reaches Europe.

An alternative measure of predictability is proposed by counting the number of members that forecast the actual storm when it reaches Europe. The closest tracks are identified on the day of maximum intensity to ensure that a track is identified in each member of the ensemble. Thresholds in position and intensity are combined to define the actual storm, with a $1: 2$ ratio between the thresholds that roughly corresponds to the ratio between the two median absolute errors (Fig. 5c and d, respectively). Using rather generous thresholds of $10^{\circ}$ great circle in distance and $20 \mathrm{hPa}$ in MSLP bias, which select about two-thirds of the reforecasts, all 25 storms are captured by almost all 11 members until day 4 (Fig. 6a). The proportion of members then decreases and passes below the majority beyond day 8 . Using more restrictive thresholds of $5^{\circ}$ great circle in distance and $10 \mathrm{hPa}$ in MSLP bias, which select about one-third of the reforecasts, the storms are captured by almost all 11 members until day 2 only and are missed by the majority of members beyond day 3 already (Fig. 6b). Albeit arbitrary, these combinations of thresholds express a reasonable range of criteria for a useful definition of the actual storm. While the exact number of members forecasting the storm will depend on the precise thresholds, these results suggest that the storms are forecasted with high certainty until days $2-4$. At longer lead times, the certainty decreases but some members still forecast the storms beyond 1 week in advance, as was already mentioned by Froude et al. (2007b). The use of subsets of the ensemble for early warnings is discussed in Sect. 4.

\subsection{Storm impact}

The predictability of the selected storms is further evaluated with respect to the impact of the wind gusts estimated from the SSI. Only the daily, spatially averaged SSI is evaluated here, without considering geographical information on where the storm occurred exactly. The reforecast is therefore evaluated for its ability to predict a severe storm on a specific day over central Europe. It is compared to ERA-Interim as a logarithmic difference because the SSI is highly nonlinear (Eq. 2) and spans several orders of magnitude between the least and the most severe storms of the selection (Table 1). As illustrated by the 95th and 99th percentiles of the model climate, the reforecast systematically overestimates the SSI of intense and extreme events by a factor of about 2 compared to ERA-Interim (dotted and dashed curves in Fig. 7a). This is explained by a longer tail of the distribution of wind gusts in the reforecast compared to ERA-Interim, which impacts the SSI despite the scaling with separate model climates between the reforecast and ERA-Interim (Eq. 2). This systematic overestimation must be taken into account to evaluate the predictability of the selected storms.

On average over all storms, the reforecast overestimates the SSI until day 3 compared to ERA-Interim but then drops by 1 order of magnitude and underestimates the SSI at longer lead times (solid curve in Fig. 7a). In contrast, the overestimation of SSI in the whole dataset does not exhibit such a drift with lead time (dotted and dashed curves). The overestimation for the storms until day 3 could therefore be corrected, as it results from a systematic bias in the dataset, while the drop on day 4 is specific to the sample of severe storms. The reforecast thus strongly underestimates the severity of the storms beyond day 3 . In addition, the average spread in SSI between ensemble members increases until day 3 only, before it decreases again when the average SSI drops (not shown). The reforecast is thus underdispersive at longer lead time. As for the track and intensity, the predicted SSI shows a large variability between the storms (symbols). 
(a) Ensemble median

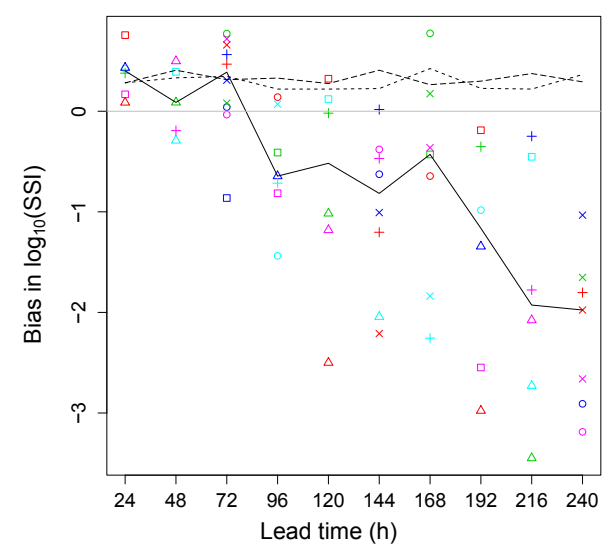

(b) SSI larger than ERA-Interim

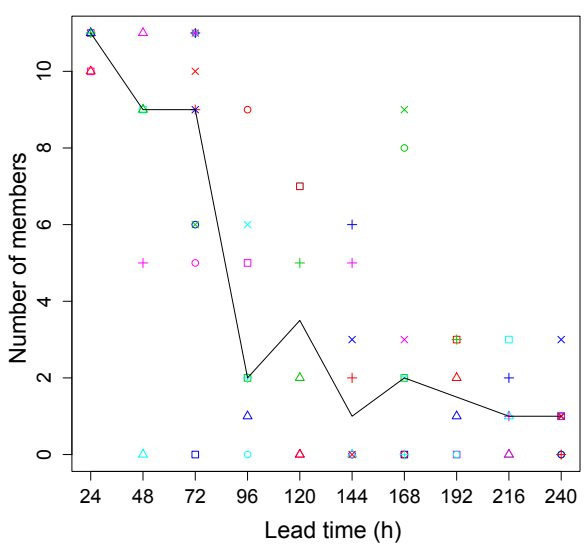

Figure 7. Severity of the storms in the ensemble reforecast on the day of maximum intensity: logarithmic difference of SSI between the ensemble median and ERA-Interim (a) and number of members reaching the SSI of ERA-Interim (b). The symbols represent the storms as given in Table 1 and the solid black curve shows the median of the storms per lead time. The dotted and dashed black curves in (a) further show the logarithmic difference of the 95th and 99th percentiles of SSI, respectively, in the model climates of the reforecast and ERA-Interim.

For instance, the deep storms Gero and Oratia are again outliers with strong negative biases at days 5,8 and 9 , whereas a few other storms even exhibit a positive bias. These results are confirmed by measuring the number of members that predict at least the SSI of ERA-Interim, which also drops at day 4 (Fig. 7b). Note that this is a rather optimistic estimation, as the predicted SSI is systematically overestimated. However, at least one ensemble member on average still predicts the ERA-Interim value of SSI of the storms until day 7, which suggests a potential for early warnings.

\section{Skill for early warnings on the 5-10 day timescale}

\subsection{Top 5 and $1 \%$ SSI events}

The results above show that even though the storms are well predicted by the whole ensemble a few days ahead only, they are forecasted by single members up to 1 week in advance or even beyond. However, these results are biased by the focus on the prediction of observed events without considering events that are predicted but not observed. In the following, the skill of the reforecast is investigated not for the selected storms but for the whole mid-Octobermid-March 1995/1996-2014/2015 dataset in order to include days both with and without storms. It is measured with the BSS split into reliability and resolution components (Eq. 1).

The skill of the reforecast is first investigated for intense events defined as the top $5 \%$ of the SSI, which contain the 78 most severe storms per winter on average. Percentiles are preferred to absolute values because of the systematic overestimation of the reforecast compared to ERA-Interim. The frequency of intense events is then by definition the same (5\%) in the reforecast than in ERA-Interim and thus the reliability component remains close to zero (perfect skill, Fig. 8a). The non-zero values reflect the sampling uncertainty. In contrast, the resolution component increases steadily with lead time to approach one (no skill). Therefore, the BSS follows - with inverted sign - the evolution of the resolution component and decreases steadily until it vanishes (no skill) at day 9. The reforecast thus clearly exhibits positive skill, albeit small, at predicting intense events until day 8 .

The skill is less clear for extreme events defined as the top $1 \%$ of the SSI. These contain the 30 most severe storms of the whole dataset and approximately match the 25 selected storms in ERA-Interim. Surprisingly, the reforecast does not show any skill at day 1 (Fig. 8b). This is linked to a high value of the resolution component (low skill) and may again be due to a problem with the spin-up of the model. The resolution component then steadily increases with increasing lead time as expected. In contrast, the reliability component shows an irregular evolution with lead time and large values reflecting a large sampling uncertainty. This emphasises that the dataset is too limited to investigate extreme events, which on average represent 8.2 events per lead time only. As a result, the BSS suggests that the reforecast exhibits some skill in predicting extreme events until day 6 but it suffers from the same irregular evolution with lead time.

\subsection{EFI and SOT for gusts above the 98th percentile}

The potential for early warnings of strong gusts is further investigated with the EFI and SOT, which are both designed for this purpose by highlighting the behaviour of the most extreme ensemble members. As noted by Lalaurette (2003), the EFI gives useful warnings of extreme events but also frequent false alarms. Petroliagis and Pinson (2014) therefore suggested the use of an optimal threshold to balance between hit rate $(H)$ and false alarm rate $(F)$, a lower or higher thresh- 

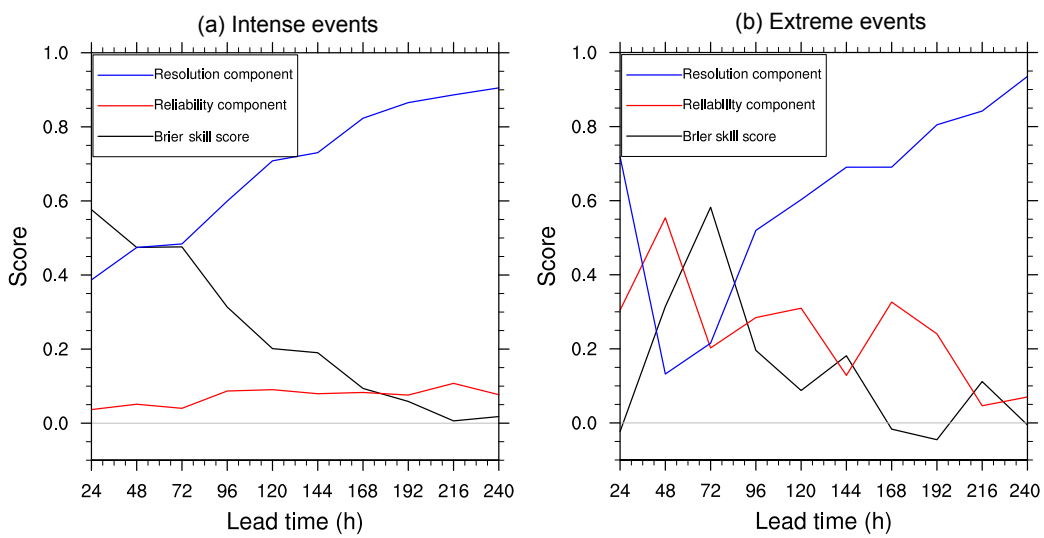

Figure 8. Brier skill score as a function of lead time for the SSI exceeding the 95th (a) and 99th percentiles of the model climatology (b). The Brier skill score is decomposed into resolution and reliability components (see Eq. 1).
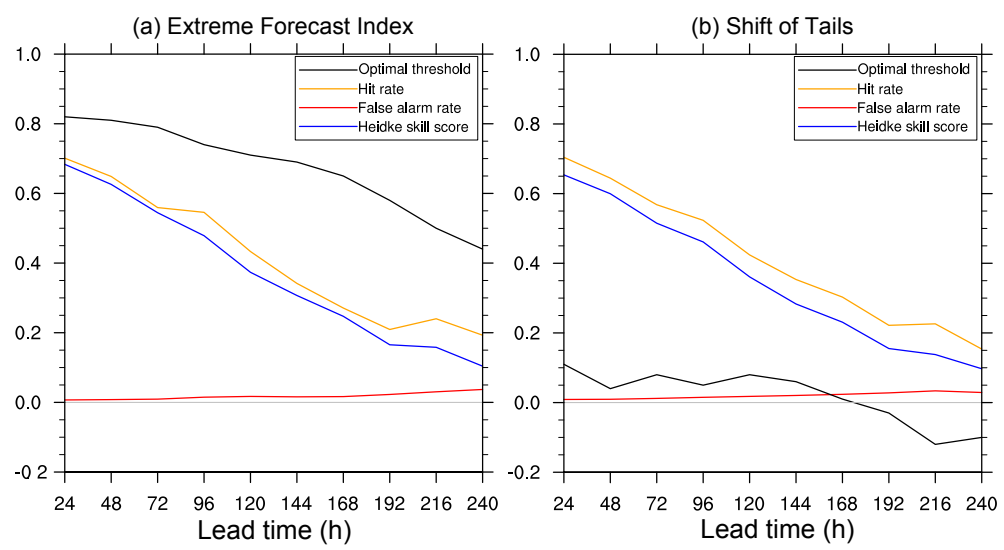

Figure 9. Optimal threshold and corresponding hit rate $(H)$, false alarm rate $(F)$ and Heidke skill score for the Extreme Forecast Index (a) and the Shift of Tails (b) to predict gusts exceeding the local 98th percentile in ERA-Interim.

old increasing or decreasing both $H$ and $F$. Boisserie et al. (2016) further suggested to maximise the Heidke skill score (HSS; Heidke, 1926) to define the optimal threshold. Following these authors, an optimal threshold is determined to predict gusts that exceed the local 98th climatological percentile in ERA-Interim. The 98th percentile represents the strength at which gusts become damaging in the SSI (Eq. 2). In contrast to the previous studies of Petroliagis and Pinson (2014) and Boisserie et al. (2016), however, which focused on specific storms or storm categories, an optimal threshold is first computed for the whole dataset and only then applied to the selected storms. This ensures that the result is not biased by verifying the forecast with extreme events only.

As shown in Fig. 9a, the optimal threshold in EFI decreases with lead time, as do the corresponding $H$ and $F$. In contrast, the optimal threshold in SOT is stable until day 6 and decreases at longer lead times only (Fig. 9b). This reveals a different balance between $H$ and $F$ for the two indices. A constant threshold is thus only suitable for the SOT and in the early range. For all other types of warnings, the dependency of the optimal thresholds on lead time should be taken into account. The optimal thresholds display seasonal and regional variability (not shown), which could also be included to improve warnings. For the sake of simplicity, however, they are not considered here.

Although the optimal threshold exhibits a different evolution with lead time between the two indices, the corresponding HSS is very similar, with a slightly higher value for the EFI. The skill decreases steadily with increasing lead time but remains positive until day 10 , the longest lead time investigated here. The decrease tightly follows $H$, while $F$ slowly increases but remains small due to the rarity of events by definition of the local 98th climatological percentile. Note that $F$, which is conditioned by the events that are not observed, should not be confused with the false alarm ratio (FAR), which is conditioned by the events that are not forecast. These results demonstrate the actual potential of both EFI and SOT for early warnings of strong gusts. If the local 99th climatological percentile is preferred to define extreme events, as in early studies, the optimal thresholds need 

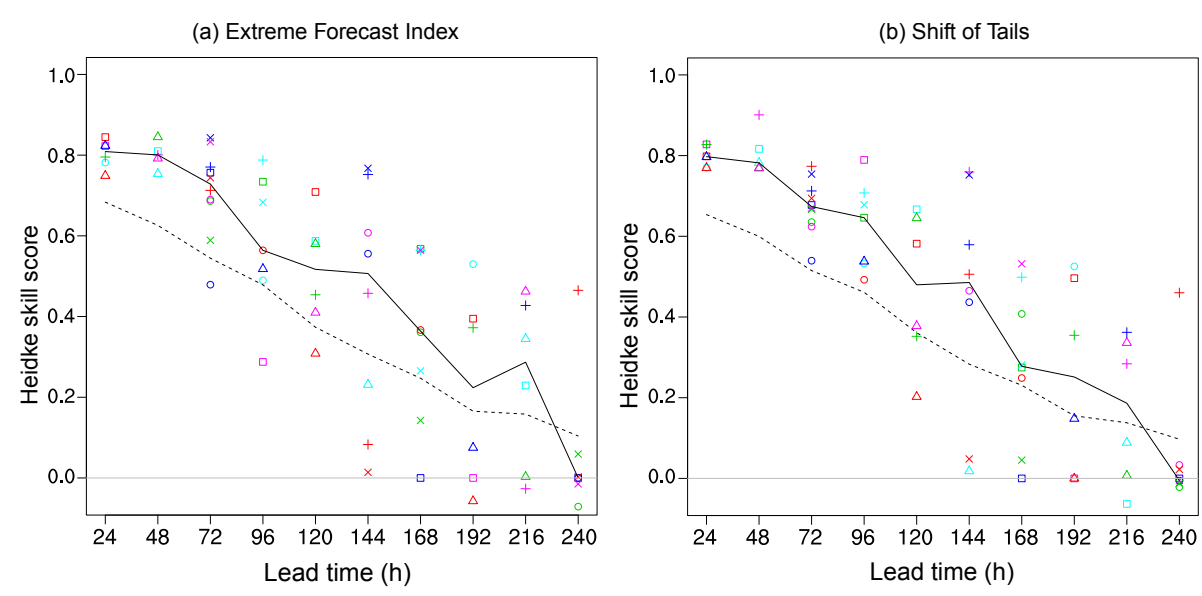

Figure 10. Heidke skill score for predicting gusts exceeding the local 98th climatological percentile of ERA-Interim using the Extreme Forecast Index (a) and the Shift Of Tails (b). The symbols represent the storms as given in Table 1 and the black curve shows the median of the storms per lead time, while the dashed curves illustrate the whole dataset for reference as in Fig. 9.

to be increased and the resulting skill becomes lower, but it also remains positive until day 10 (not shown).

\subsection{EFI and SOT for the 25 severe storms}

In order to explore possible links between predictability and physical characteristics of storms, the optimal thresholds described above are applied to the EFI and SOT for the selected severe storms in the reforecast. The HSS is again used as a trade-off between $H$ and $F$. It is computed for the prediction of gusts over the central European domain on the day of maximum intensity of each storm. As for the whole dataset, the EFI (Fig. 10a) and the SOT (Fig. 10b) exhibit a similar HSS on average, which lies around 0.8 during the first 2 days (high skill) and then decreases with increasing lead time until vanishing at day 10 (no skill). In particular, before day 10 , the HSS is higher for the storms (solid curves) than for the whole dataset (dashed curves). It is related to higher $\mathrm{H}$ for the storms, which enhance the skill despite higher $F$ (not shown). This does not necessarily mean that the reforecast is more skillful at predicting the presence than the absence of storms but rather emphasises how focusing on observed events can bias the verification.

Beyond these average properties, the reforecasts of the storms exhibit contrasting skill from case to case. The variability between the storms quickly increases with increasing lead time and the HSS of some storms approaches zero or becomes negative from day 6 onwards (symbols on Fig. 10). A poor skill is found in both EFI and SOT for storms Lili at day 7 (blue square) and Gero at day 8 (red triangle) in association with a low $H$, as well as for storm Joachim at day 7 (green cross) in association with a high $F$. This is consistent with the large biases in MSLP and longitude and the large spread in MSLP, respectively, found for these storms (Fig. 5). Other storms contrast between poor skill in EFI and good skill in SOT, as Yuma at day 4 (pink square in Fig. 10), which was noted for its difficult forecast as it occurred (Young and Grahame, 1999), and Xynthia at day 6 (red plus). The higher skill in these cases could be due to the higher $H$ of the SOT compared to the EFI, as suggested by Boisserie et al. (2016), although no difference is found here on average in the whole sample.

Interestingly, storms Yuma, Lili, Gero and Xynthia mentioned above for their poor skill in EFI have the smallest area of strong gusts of the whole dataset (Table 1). Similarly, a better performance for Anatol than for the relatively smaller storms Lothar and Martin was previously noted by Buizza and Hollingsworth (2002) in the operational ECMWF ensemble forecast. However, neither this better performance nor differences between the predictability of specific storms found by other authors using the EFI (Lalaurette, 2003; Petroliagis and Pinson, 2014; Boisserie et al., 2016) are confirmed here. This suggests a sensitivity to the ensemble prediction system and to the type and region of the reference data used for their validation, which vary from study to study.

Finally, storm Xynthia exhibits a surprisingly high skill at day 10 in both EFI and SOT thanks to a high $H$. This constitutes an outlier compared to all other storms, which show no skill at that lead time. However, none of the ensemble members predicts the observed development of Xynthia over the subtropical North Atlantic (Ludwig et al., 2014). Instead, several members predict a storm forming over the central North Atlantic but reaching the Iberian Peninsula on the same day as Xynthia. Although this successful reforecast could be due to chance rather than to the actual skill of the model, it illustrates how predicting individual storms becomes ambiguous at long range but suggests a potential for predicting an environment favourable to storm development. 


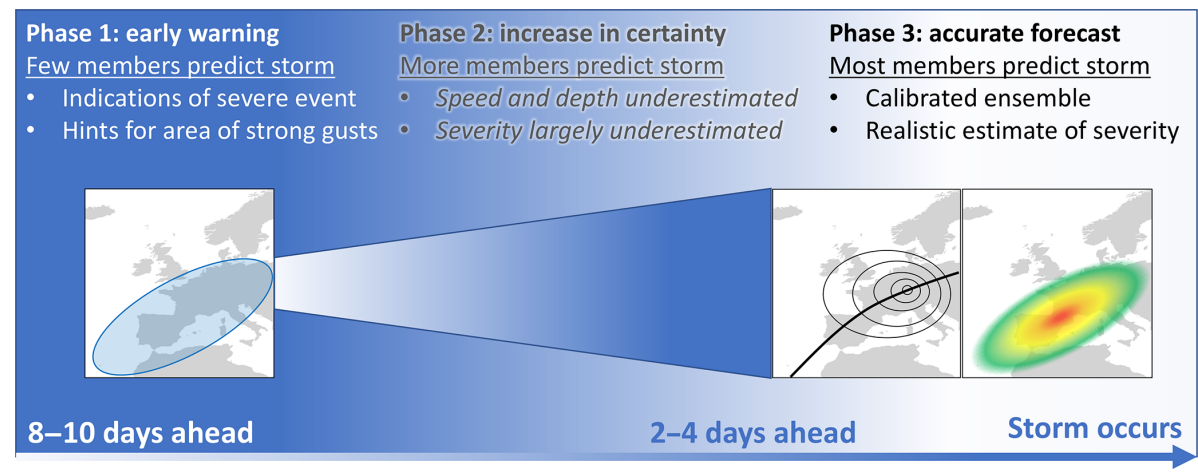

Figure 11. Summary of the expected skill of an ensemble prediction system for the forecast of severe European winter storms, from long to short forecast lead times separated in three phases. The schematic refers to the three methods depicted in Fig. 1.

\section{Conclusions}

The synoptic-scale predictability of 25 severe historical winter storms over central Europe is revisited by taking advantage of the ECMWF ensemble retrospective forecast (reforecast), which offers a homogeneous dataset over 20 years with a state-of-the-art ensemble prediction system. The predictability of the storms is investigated with three different metrics for their track and intensity (Fig. 1a), the strength of wind gusts (Fig. 1b) and the area covered by strong gusts (Fig. 1c). The metrics are combined to assess the reforecast against the ECMWF reanalysis ERA-Interim.

For lead times until 3-4 days, the ensemble average has small biases in terms of predicting the position and minimum MSLP of the storms on the day of maximum intensity. At longer lead times, it systematically underestimates the speed of motion and the depth of the storms. Previous studies also found a slow bias in the track forecasts of extratropical cyclones in general (Froude et al., 2007b) and a negative bias in the intensity forecasts of severe storms only (Pirret et al., 2017). This suggests that the underestimation of the speed of motion is systematic but that of the depth is specific to deep cyclones. The ensemble average further underestimates the SSI of the storms by at least one order of magnitude beyond day 3. Along with the biases with increasing lead time, the identification of storms becomes ambiguous and the number of members containing the observed storms decreases, which questions the limit of validity of the ensemble mean for the track of the storms. This limit is due to the identification of storms as objects, which are not always clearly defined, in contrast to the metrics based on the strength of wind gusts, which are defined even in the absence of a storm. The predictability is further measured by the number of members that forecast the observed storm - within combined thresholds in position and intensity - on the day it reaches Europe. Although the result depends on the exact thresholds, reasonable values show that the storms are well forecasted until days $2-4$ only. These results suggest that relevant predictions of storm properties are restricted to the first few days of the forecast.

A different method is therefore required for lead times longer than the horizon of 2-4 days. The position, intensity and severity of the storms are captured by some members beyond 1 week in advance, which suggests potential for early warning. The whole distribution of the ensemble shall thus be used by shifting the focus from the average to individual members for the prediction of extreme events (Buizza and Hollingsworth, 2002; Lalaurette, 2003; Petroliagis and Pinson, 2014; Boisserie et al., 2016). The danger with this approach, however, is to verify the predictions with regard to their ability to forecast observed events without accounting for events that are forecasted but not observed. The predictability is therefore investigated here in the whole dataset of 20 winter seasons including both stormy and non-stormy days. Using the EFI and SOT indices, which highlight the most extreme ensemble members, the reforecast shows skill in predicting the area covered by strong gusts until days 910. It is also skillful until day 8 to predict the occurrence of intense events defined as the top $5 \%$ of the SSI (spanning on average 7-8 days per winter). However, for extreme events defined as the top $1 \%$ of the SSI (approximately corresponding to the 25 selected storms), no meaningful results can be obtained due to the large sampling uncertainty. Despite this limitation for the most extreme events, the results confirm the skill for early warnings of storms beyond 1 week ahead.

These results are summarised in Fig. 11 from long to short forecast lead times separated in three phases. A first phase of early warning starts $8-10$ days before a storm occurs. At this point, a few members may already predict the storm, which gives indications of the possibility of a severe event based on the SSI, as well as hints for the area that might be covered by strong gusts given by the EFI and SOT. In a second phase, the number of members predicting the storm increases but biases are present in the speed of motion and in the intensity measured as the MSLP of the storm, which are both systematically underestimated. The severity of the storm measured by the SSI is also underestimated by one or more orders of 
magnitude. The certainty then increases until the third phase of accurate forecast, starting 2-4 days before the storm occurs. Most members predict the storm and without systematic bias at this point, which allows a calibrated forecast for the position and intensity of the storm and a realistic estimate of its severity. These three phases in the expected skill of an ensemble prediction system may serve as a reference to forecast severe European winter storms in an operational context.

Among the sample of 25 severe storms, some outliers exhibit a particularly low predictability. These are storms involving an explosive cyclogenesis or extending over a small area, as well as a storm undergoing extratropical transition. Unfortunately, the sample is too small and the number of forecasts per storm is too limited for any robust statistics. The NOAA ensemble reforecast could help to identify systematic links between the dynamics and predictability of storms, as it covers a longer period and offers a daily initialization (Hamill et al., 2013). However, this dataset appears not to perform as well as its ECMWF counterpart for predicting wind over central Europe (Dabernig et al., 2015). The operational ECMWF ensemble forecast is initialised twice a day and contains 50 members but Pirret et al. (2017) struggled to find a relation between the predictability and the intensity, track or physical processes of storms because of the steady increase in skill with more recent model versions. This illustrates the difficulty in systematically investigating the predictability of severe storms, even with an extended dataset such as the 20-year reforecast used here.

More case studies are thus needed to better understand the predictability of specific storm features at different scales. At larger scale, the focus of the predictability could be shifted from the storms to the conditions that favour their development (e.g. Pinto et al., 2014). This could be particularly relevant at long lead times, when the identification of storms becomes ambiguous among the ensemble members. At smaller scale, the use of available high-resolution model data can help to better understand the structure of the storms. For instance, the next generation of ECMWF reanalysis, ERA5, which is currently in production, will reach a horizontal grid spacing of about $30 \mathrm{~km}$ and improve the representation of synoptic-scale features. Regional models are required to represent mesoscale features such as sting jets or convection embedded in the cold front, while the accurate representation of wind gusts stays beyond the resolution of operational models and relies on large-eddy simulations or observations at the turbulent scale. Alternatively, dynamical and statistical downscaling can be combined to obtain skillful forecasts at the local level, as demonstrated by Pardowitz et al. (2016) for storm losses, who further took both meteorological and damage model uncertainties into account. These different approaches shall be considered to allow advances in the predictability of severe European winter storms.
Data availability. The ERA-Interim dataset is publicly available at http://apps.ecmwf.int/datasets/data/interim-full-daily. Parts of the ECMWF ensemble reforecast dataset are also publicly available from the sub-seasonal to seasonal (S2S) prediction project at http://apps.ecmwf.int/datasets/data/s2s, while variables used in this study require direct access to the ECMWF Meteorological archive (MARS).

Author contributions. FP, PK and UC defined the scientific scope of the study. FP performed the data analysis and wrote the paper. All authors discussed the results and commented on the paper.

Competing interests. The authors declare that they have no conflict of interest.

Acknowledgements. ECMWF is acknowledged for providing the ensemble reforecast and ERA-Interim reanalysis datasets. The authors thank Philippe Arbogast, Dale Durran, Tim Hewson and Joaquim Pinto for discussions about the interpretation of the results, as well as two anonymous reviewers for comments that helped improving the manuscript. The research leading to these results has been done within the subproject C5 "Forecast uncertainty for peak surface gusts associated with European cold-season cyclones" of the Transregional Collaborative Research Center SFB/TRR 165 "Waves to Weather" funded by the German Research Foundation (DFG).

The article processing charges for this open-access publication were covered by a Research Centre of the Helmholtz Association.

Edited by: Ricardo Trigo

Reviewed by: two anonymous referees

\section{References}

Bechtold, P. and Bidlot, J.-R.: Parametrization of convective gusts, ECMWF Newsl., 119, 15-18, https://doi.org/10.21957/kfr42kfp8c, 2009.

Boisserie, M., Descamps, L., Arbogast, P., Boisserie, M., Descamps, L., and Arbogast, P.: Calibrated forecasts of extreme windstorms using the Extreme Forecast Index (EFI) and Shift of Tails (SOT), Weather Forecast., 31, 1573-1589, https://doi.org/10.1175/WAF-D-15-0027.1, 2016.

Brier, G. W.: Verification of forecasts expressed in terms of probability, Mon. Weather Rev., 78, 1-3, https://doi.org/10.1175/15200493(1950)078<0001:VOFEIT>2.0.CO;2, 1950.

Browning, K. A.: The sting at the end of the tail: Damaging winds associated with extratropical cyclones, Q. J. Roy. Meteorol. Soc., 130, 375-399, https://doi.org/10.1256/qj.02.143, 2004.

Browning, K. A., Panagi, P., and Vaughan, G.: Analysis of an extropical cyclone after its reintensification as a warm-core extratropical cyclone, Q. J. Roy. Meteorol. Soc., 124, 2329-2356, https://doi.org/10.1002/qj.49712455108, 1998. 
Buizza, R. and Hollingsworth, A.: Storm prediction over Europe using the ECMWF Ensemble Prediction System, Meteorol. Appl., 9, 289-305, https://doi.org/10.1017/S1350482702003031, 2002.

Dabernig, M., Mayr, G. J., and Messner, J. W.: Predicting wind power with reforecasts, Weather Forecast., 30, 1655-1662, https://doi.org/10.1175/WAF-D-15-0095.1, 2015.

Dee, D. P., Uppala, S. M., Simmons, A. J., Berrisford, P., Poli, P., Kobayashi, S., Andrae, U., Balmaseda, M. A., Balsamo, G., Bauer, P., Bechtold, P., Beljaars, A. C. M., van de Berg, L., Bidlot, J., Bormann, N., Delsol, C., Dragani, R., Fuentes, M., Geer, A. J., Haimberger, L., Healy, S. B., Hersbach, H., Hólm, E. V., Isaksen, L., Kållberg, P., Köhler, M., Matricardi, M., McNally, A. P., Monge-Sanz, B. M., Morcrette, J.-J., Park, B.-K., Peubey, C., de Rosnay, P., Tavolato, C., Thépaut, J.-N., and Vitart, F.: The ERA-Interim reanalysis: configuration and performance of the data assimilation system, Q. J. Roy. Meteorol. Soc., 137, 553597, https://doi.org/10.1002/qj.828, 2011.

Della-Marta, P. M., Mathis, H., Frei, C., Liniger, M. A., Kleinn, J., and Appenzeller, C.: The return period of wind storms over Europe, Int. J. Climatol., 29, 437-459, https://doi.org/10.1002/joc.1794, 2009.

Donat, M. G., Pardowitz, T., Leckebusch, G. C., Ulbrich, U., and Burghoff, O.: High-resolution refinement of a storm loss model and estimation of return periods of loss-intensive storms over Germany, Nat. Hazards Earth Syst. Sci., 11, 2821-2833, https://doi.org/10.5194/nhess-11-2821-2011, 2011.

Feser, F., Barcikowska, M., Krueger, O., Schenk, F., Weisse, R., and Xia, L.: Storminess over the North Atlantic and northwestern Europe-A review, Q. J. Roy. Meteorol. Soc., 141, 350-382, https://doi.org/10.1002/qj.2364, 2015.

Fink, A. H., Brücher, T., Ermert, V., Krüger, A., and Pinto, J. G.: The European storm Kyrill in January 2007: synoptic evolution, meteorological impacts and some considerations with respect to climate change, Nat. Hazards Earth Syst. Sci., 9, 405-423, https://doi.org/10.5194/nhess-9-405-2009, 2009.

Froude, L. S. R., Bengtsson, L., and Hodges, K. I.: The predictability of extratropical storm tracks and the sensitivity of their prediction to the observing system, Mon. Weather Rev., 135, 315-333, https://doi.org/10.1175/MWR3274.1, 2007a.

Froude, L. S. R., Bengtsson, L., and Hodges, K. I.: The prediction of extratropical storm tracks by the ECMWF and NCEP Ensemble Prediction Systems, Mon. Weather Rev., 135, 2545-2567, https://doi.org/10.1175/MWR3422.1, 2007b.

Gatzen, C., Púčik, T., and Ryva, D.: Two cold-season derechoes in Europe, Atmos. Res., 100, 740-748, https://doi.org/10.1016/j.atmosres.2010.11.015, 2011.

Haas, R. and Pinto, J. G.: A combined statistical and dynamical approach for downscaling large-scale footprints of European windstorms, Geophys. Res. Lett., 39, L23804, https://doi.org/10.1029/2012GL054014, 2012.

Hagedorn, R., Hamill, T. M., Whitaker, J. S., Hagedorn, R., Hamill, T. M., and Whitaker, J. S.: Probabilistic forecast calibration using ECMWF and GFS ensemble reforecasts. Part I: Two-Meter Temperatures, Mon. Weather Rev., 136, 2608-2619, https://doi.org/10.1175/2007MWR2410.1, 2008.

Hagedorn, R., Buizza, R., Hamill, T. M., Leutbecher, M., and Palmer, T. N.: Comparing TIGGE multimodel forecasts with reforecast-calibrated ECMWF ensemble forecasts, Q. J. Roy. Meteorol. Soc., 138, 1814-1827, https://doi.org/10.1002/qj.1895, 2012.

Hamill, T. M., Whitaker, J. S., Mullen, S. L., Hamill, T. M., Whitaker, J. S., and Mullen, S. L.: Reforecasts: an important dataset for improving weather predictions, B. Am. Meteorol. Soc., 87, 33-46, https://doi.org/10.1175/BAMS-87-1-33, 2006.

Hamill, T. M., Bates, G. T., Whitaker, J. S., Murray, D. R., Fiorino, M., Galarneau, T. J., Zhu, Y., and Lapenta, W.: NOAA's second-generation global medium-range ensemble reforecast dataset, B. Am. Meteorol. Soc., 94, 1553-1565, https://doi.org/10.1175/BAMS-D-12-00014.1, 2013.

Heidke, P.: Berechnung des Erfolges und der Güte der Windstärkevorhersagen im Sturmwarnungsdienst, Geogr. Ann., 8, 301-349, https://doi.org/10.2307/519729, 1926.

Hewson, T. D. and Neu, U.: Cyclones, windstorms and the IMILAST project, Tellus A, 6, 1-33, https://doi.org/10.3402/tellusa.v67.27128, 2015.

Hofherr, T. and Kunz, M.: Extreme wind climatology of winter storms in Germany, Clim. Res., 41, 105-123, https://doi.org/10.3354/cr00844, 2010.

Jolliffe, I. T. and Stephenson, D. B.: Forecast verification: a practitioner's guide in atmospheric science, Wiley-Blackwell, Chichester, UK, 2012.

Klawa, M. and Ulbrich, U.: A model for the estimation of storm losses and the identification of severe winter storms in Germany, Nat. Hazards Earth Syst. Sci., 3, 725-732, https://doi.org/10.5194/nhess-3-725-2003, 2003.

Lalaurette, F.: Early detection of abnormal weather conditions using a probabilistic extreme forecast index, Q. J. Roy. Meteorol. Soc., 129, 3037-3057, https://doi.org/10.1256/qj.02.152, 2003.

Lamb, H. H. and Frydendahl, K.: Historic storms of the North Sea, British Isles and Northwest Europe, Cambridge University Press, Cambridge, UK, 1991.

Lamberson, W. S., Torn, R. D., Bosart, L. F., and Magnusson, L.: Diagnosis of the source and evolution of medium-range forecast errors for extratropical cyclone Joachim, Weather Forecast., 31, 1197-1214, https://doi.org/10.1175/WAF-D-16-0026.1, 2016.

Leckebusch, G. C., Ulbrich, U., Fröhlich, L., and Pinto, J. G.: Property loss potentials for European midlatitude storms in a changing climate, Geophys. Res. Lett., 34, L05703, https://doi.org/10.1029/2006GL027663, 2007.

Ludwig, P., Pinto, J. G., Reyers, M., and Gray, S. L.: The role of anomalous SST and surface fluxes over the southeastern North Atlantic in the explosive development of windstorm Xynthia, Q. J. Roy. Meteorol. Soc., 140, 1729-1741, https://doi.org/10.1002/qj.2253, 2014.

Murphy, A. H.: A new vector partition of the probability score, J. Appl. Meteorol., 12, 595-600, https://doi.org/10.1175/15200450(1973)012<0595:ANVPOT>2.0.CO;2, 1973.

Murray, R. and Simmonds, I.: A numerical scheme for tracking cyclone centres from digital data. Part I: development and operation of the scheme, Aust. Meteorol. Mag., 39, 155-166, 1991.

Neu, U., Akperov, M. G., Bellenbaum, N., Benestad, R., Blender, R., Caballero, R., Cocozza, A., Dacre, H. F., Feng, Y., Fraedrich, K., Grieger, J., Gulev, S., Hanley, J., Hewson, T., Inatsu, M., Keay, K., Kew, S. F., Kindem, I., Leckebusch, G. C., Liberato, M. L. R., Lionello, P., Mokhov, I. I., Pinto, J. G., Raible, C. C., Reale, M., Rudeva, I., Schuster, M., Simmonds, I., Sinclair, M., Sprenger, M., Tilinina, N. D., Trigo, I. F., Ulbrich, S., 
Ulbrich, U., Wang, X. L., and Wernli, H.: IMILAST: a community effort to intercompare extratropical cyclone detection and tracking algorithms, B. Am. Meteorol. Soc., 94, 529-547, https://doi.org/10.1175/BAMS-D-11-00154.1, 2013.

Panofsky, H. A., Tennekes, H., Lenschow, D. H., and Wyngaard, J. C.: The characteristics of turbulent velocity components in the surface layer under convective conditions, Bound.-Lay. Meteorol., 11, 355-361, https://doi.org/10.1007/BF02186086, 1977.

Pantillon, F., Chaboureau, J.-P., Lac, C., and Mascart, P.: On the role of a Rossby wave train during the extratropical transition of hurricane Helene (2006), Q. J. Roy. Meteorol. Soc., 139, 370386, https://doi.org/10.1002/qj.1974, 2013.

Pardowitz, T., Osinski, R., Kruschke, T., and Ulbrich, U.: An analysis of uncertainties and skill in forecasts of winter storm losses, Nat. Hazards Earth Syst. Sci., 16, 2391-2402, https://doi.org/10.5194/nhess-16-2391-2016, 2016.

Petroliagis, T. I. and Pinson, P.: Early warnings of extreme winds using the ECMWF Extreme Forecast Index, Meteorol. Appl., 21, 171-185, https://doi.org/10.1002/met.1339, 2014.

Pinto, J. G., Spangehl, T., Ulbrich, U., and Speth, P.: Sensitivities of a cyclone detection and tracking algorithm: individual tracks and climatology, Meteorol. Z., 14, 823-838, https://doi.org/10.1127/0941-2948/2005/0068, 2005.

Pinto, J. G., Gómara, I., Masato, G., Dacre, H. F., Woollings, T., and Caballero, R.: Large-scale dynamics associated with clustering of extratropical cyclones affecting Western Europe, J. Geophys. Res.-Atmos., 119, 704-719, https://doi.org/10.1002/2014JD022305, 2014.

Pirret, J. S. R., Knippertz, P., and Trzeciak, T. M.: Drivers for the deepening of severe European windstorms and their impacts on forecast quality, Q. J. Roy. Meteorol. Soc., 143, 309-320, https://doi.org/10.1002/qj.2923, 2017.

Raible, C. C., Della-Marta, P. M., Schwierz, C., Wernli, H., Blender, R., Raible, C. C., Della-Marta, P. M., Schwierz, C., Wernli, H., and Blender, R.: Northern hemisphere extratropical cyclones: a comparison of detection and tracking methods and different reanalyses, Mon. Weather Rev., 136, 880-897, https://doi.org/10.1175/2007MWR2143.1, 2008.
Roberts, J. F., Champion, A. J., Dawkins, L. C., Hodges, K. I., Shaffrey, L. C., Stephenson, D. B., Stringer, M. A., Thornton, H. E., and Youngman, B. D.: The XWS open access catalogue of extreme European windstorms from 1979 to 2012, Nat. Hazards Earth Syst. Sci., 14, 2487-2501, https://doi.org/10.5194/nhess14-2487-2014, 2014.

Seregina, L. S., Haas, R., Born, K., and Pinto, J. G.: Development of a wind gust model to estimate gust speeds and their return periods, Tellus A, 66, 22905, https://doi.org/10.3402/tellusa.v66.22905, 2014.

Stucki, P., Brönnimann, S., Martius, O., Welker, C., Imhof, M., von Wattenwyl, N., and Philipp, N.: A catalog of highimpact windstorms in Switzerland since 1859, Nat. Hazards Earth Syst. Sci., 14, 2867-2882, https://doi.org/10.5194/nhess14-2867-2014, 2014.

Stucki, P., Dierer, S., Welker, C., Gómez-Navarro, J. J., Raible, C. C., Martius, O., and Brönnimann, S.: Evaluation of downscaled wind speeds and parameterised gusts for recent and historical windstorms in Switzerland, Tellus A, 68, 31820, https://doi.org/10.3402/tellusa.v68.31820, 2016.

Wernli, H., Dirren, S., Liniger, M. A., and Zillig, M.: Dynamical aspects of the life cycle of the winter storm 'Lothar' (2426 December 1999), Q. J. Roy. Meteorol. Soc., 128, 405-429, https://doi.org/10.1256/003590002321042036, 2002.

Young, M. V. and Grahame, N. S.: Forecasting the Christmas Eve storm 1997, Weather, 54, 382-391, https://doi.org/10.1002/j.1477-8696.1999.tb03999.x, 1999.

Zsótér, E.: Recent developments in extreme weather forecasting, ECMWF Newslett., 107, 8-17, 2006.

Zsoter, E., Pappenberger, F., and Richardson, D.: Sensitivity of model climate to sampling configurations and the impact on the Extreme Forecast Index, Meteorol. Appl., 22, 236-247, https://doi.org/10.1002/met.1447, 2015. 